\title{
O desenvolvimento das competências de líderes globais: Uma abordagem baseada nos estudos de global mindset leadership
}

\author{
Mattheus Fontana Winck ${ }^{1}$, Cristiane Froehlich, \\ Maria Cristina Bohnenberger, Vania Gisele Bessi e Dusan Schreiber
}

Universidade Feevale, Novo Hamburgo, RS, Brasil.

\section{DETALHES DO ARTIGO}

\section{Histórico do artigo:}

Recebido em 5 de outubro de 2015

Aceito em 25 de abril de 2016

Disponível online em 31 de agosto de 2016

Sistema de Revisão "Double Blind Review"

Editor científico:

Eduardo Eugênio Spers

\section{Palavras-chaves:}

Global mindset leadership

Globalização

Competências

Liderança

\begin{abstract}
RESUMO
A necessidade de líderes globais é um tema discutido nas organizações. O Global Mindset Leadership é um manual de desenvolvimento de competências do líder global que deve ser capaz de transcender as barreiras nacionais e empresariais para integrar diversas perspectivas e pessoas e de se adaptar a quaisquer ambientes. Estar ciente das evoluções que ocorrem no mercado é tarefa dos líderes, que devem se adaptar e compreender diferentes sistemas culturais. O objetivo desta pesquisa é analisar a percepção do desenvolvimento das competências dos líderes globais, na dimensão intelectual, psicológica e social, a partir de profissionais que atuam tanto no ambiente acadêmico quanto empresarial. Classifica-se essa pesquisa como pesquisa de campo, descritiva e com abordagem qualitativa. A principal contribuição dessa pesquisa foi compreender que os líderes globais são identificados através de competências que os fazem ser mutáveis, ou seja, com alto grau de adaptação a novos contextos e pessoas. A partir de uma visão de líderes globais atuantes em uma universidade na Coréia do Sul, foi possível caracterizar, tanto sob a perspectiva acadêmica como organizacional o perfil desejado de um líder global.
\end{abstract}

(C) 2016 Internext | ESPM. Todos os direitos reservados!

\section{Introdução}

Contemporaneamente, aumentou-se o interesse das organizações em líderes com competências para se adaptar e serem eficientes em empresas transnacionais. Javidan e Walker (2013) abordam que a diversidade e complexidade do século $X X$, apresenta inúmeras e imprevisíveis oportunidades de interações globais para os negócios. Para isso, necessitam-se de líderes capazes de integrar sistemas e transitar adequadamente em diversas culturas, pois o líder global é compreendido como alguém que transcende diferenças culturais para criar uma prosperidade sustentável em nível mundial.

A necessidade de um líder global adaptável e capaz de desenvolver competências com o propósito de administrar com efetividade a integração de diversas culturas é alvo de estudos recentes (Hitt, Javidan, \& Steers, 2007; Bradberry \& Greaves, 2012; Cantrell \& Lucas, 2007; Charan, Drotter, \& Noel, 2011; Fernandes, 2013; Javidan \& Walker, 2013). Neste contexto o Global Mindset Leadership traduzido na presente pesquisa para "líder global", de Javidan e Walker (2013), é utilizado como referência para complementar os estudos já realizados nesta área.

O estudo se demonstra necessário pois contempla um recurso estratégico importante para as organizações: os seus líderes. Os processos de formação devem privilegiar as competências que 
resultem em efetividade e aceitabilidade de um líder em qualquer contexto econômico ou cultural.

Diante disso, formulou-se a seguinte questão de pesquisa: qual a percepção de líderes globais sobre o desenvolvimento de competências das dimensões intelectual, psicológica e social - para exercer a liderança em um contexto global? O objetivo da pesquisa é analisar a percepção do desenvolvimento das competências dos líderes globais, na dimensão intelectual, psicológica e social, a partir de profissionais que atuam tanto no âmbito acadêmico quanto empresarial. Para isto foram selecionados cinco líderes globais americanos e residentes na Coréia do Sul, em Pusan, que são especialistas em temas correlatos e foram e/ou são líderes globais em organizações. Os sujeitos selecionados também atuam no âmbito acadêmico na área de estudos internacionais. O estudo apresenta um caráter descritivo e pode ser caracterizado como pesquisa de campo qualitativa.

A principal contribuição do estudo se dá pela indicação das competências mais significativas, e como podem ser desenvolvidas, a partir de atores que vivenciam tanto o ambiente empírico, quanto o ambiente acadêmico. Indicando alternativas de formação para os gestores globais. Para construir esta abordagem a escolha dos atores que tem atuação nos dois ambientes foi relevante e possuem diferenças culturais significativas em relação aos países de origem e atuação.

O artigo está dividido em cinco sessões: introdução, que faz uma apresentação do estudo; o embasamento teórico, onde busca-se a contextualização do tema; o método de pesquisa; a análise dos resultados, onde são abordadas as reflexões a partir dos resultados obtidos com os respondentes; e as considerações finais.

\section{Líder global}

A liderança é a capacidade de um indivíduo em influenciar, motivar e permitir que outros contribuam para a efetividade e sucesso da empresa a qual pertencem (House, Javidan, Hanges, \& Dorfman, 2002). Essa influência se dá em perspectiva global pelo processo de instigar indivíduos, grupos e organizações dentro e fora das fronteiras nacionais, representando diversos sistemas políticos, institucionais e, principalmente, culturais (Hitt, Javidan, \& Steers, 2007).
A compreensão do líder global como principal agente no meio empresarial vem chamando a atenção de executivos e estudiosos, pois percebe-se nesses líderes um potencial para melhorar os resultados da empresa, bem como aprimorar a sincronização das culturas nela presentes a fim de se criar um sistema harmonioso (McCall \& Hollenbeck, 2002; Fernandes, 2013).

Para isso o líder global necessita de um conjunto de atributos e características que os ajudam a influenciar melhor as pessoas, grupos e organizações diferentes deles (Javidan \& Walker, 2013). A efetividade exercida pelo líder global na empresa dependerá da competência dele em combinar as diferenças culturais, as rotinas e hábitos existentes (House et al., 2002). O conceito de competência neste contexto compreende $o$ alcance de resultados em ambientes multiculturais, sob as diversas circunstâncias de internacionalização (Hitt, Javidan, \& Steers, 2007).

A necessidade de um líder global adaptável e capaz de desenvolver competências com o propósito de administrar com efetividade a integração de diversas culturas é alvo de estudos recentes. Precisase de um modelo que transcenda o mercado doméstico e integre sistemas nacionais, regionais e individuais, tornando-se uma ferramenta para formação, desenvolvimento, imersão e retenção de potenciais líderes globais pautados na ética em relações interpessoais (Hitt, Javidan, \& Steers, 2007; Bradberry \& Greaves, 2012; Cantrell \& Lucas, 2007; Charan, Drotter, \& Noel, 2011; Fernandes, 2013; Javidan \& Walker, 2013).

Ao longo dos anos foram apresentados diversos modelos para compor o perfil de líder global. Estudos relevantes nesse sentido constituem os modelos: empreendedor (Andersson, 2000), Global Mindset em sete competências (McCall \& Hollenbeck, 2002), construtivista (Harris \& Kunhert, 2007), proficiência do líder global (Chong, 2008), e o modelo Global Mindset Leadership (Javidan \& Walker, 2013) que evoluiu do modelo teórico do líder global (House et al., 2002). Andersson (2000) descreve o líder global como um indivíduo administrador de visões empreendedoras. Seu modelo baseia-se em cinco competências: i) visualização de novas combinações; ii) vontade de agir e desenvolver essas novas combinações; iii) visão de que agir de acordo com as percepções do outro é mais importante do que ações baseadas na racionalidade própria; iv) convencer 
outros a investirem em projetos empreendedores; e v) noção de tempo apropriada para oportunidades. A teoria empreendedora é utilizada para analisar o comportamento internacional da empresa.

McCall e Hollenbeck (2002) descrevem o líder global como uma pessoa talentosa, que deve possuir talento para ser desenvolvido, deve agregar experiência adquirida, alinhada com a estratégia da organização; e a experiência deverá ser a catalisadora do processo. Nota-se que o modelo aponta que o desenvolvimento de competências direciona os talentos e experiências do líder global à eficiência na organização o que é possibilitado através de experiências.

O modelo construtivista de Harris e Kunhert (2007) baseia-se no desenvolvimento de competências do líder global através de níveis, sendo unidirecionais e invariáveis. No primeiro nível o líder busca a autocompreensão, compreensão do outro e do mundo; então o líder passa a obter o reconhecimento do ponto de vista de outras pessoas; assim, ele possui a compreensão através de independência racional, e habilidade de criar laços com pessoas estrangeiras para tomada de decisões; ao final, líderes demonstram um novo entendimento de mundo. Para Harris e Kunhert (2007) os líderes globais devem ter como competência: o autoconhecimento; abertura para mudanças, inspirar comprometimento; criar visões convincentes; liderar mudanças; cultivar e reter talentos; catalisar times; e administrar performance.

No modelo de proficiência do líder global, desenvolvido por Chong (2008), foram definidas doze competências necessárias para o líder global, separadas através de quatro dimensões: i) administrativa (gestão do tempo; definição de objetivos e padrões de desempenho; planejamento e escalonamento do trabalho); ii) comunicativa (saber ouvir e organizar pensamentos; dar informações claras; receber informações imparciais); iii) gestão das pessoas (treinamento, monitoramento e delegação de tarefas; avaliação de pessoas e performance e; disciplina e aconselhamento); e, iv) cognitiva (identificação e solução de problemas; tomada de decisões e avaliação de riscos e; pensamento claro e analítico).

House et al. (2002) apresentam um modelo teórico baseado na aceitação e efetividade do líder global. A partir da percepção de relevância do líder global em um modelo teórico, Hitt, Javidan e Steers
(2007) identificaram a necessidade de examinar o tema da construção do líder global para compreensão de seu conteúdo. Os autores abordam - líder global a partir de uma perspectiva de competências individuais, que combinadas, habilitam líderes globais a obter sucesso em influenciar pessoas de diferentes partes do mundo e diferentes culturas a trabalharem juntas para atingir os objetivos organizacionais. Estas competências são separadas em três dimensões (capitais), caracterizando o inventário do líder global (Global Mindset Inventory), que são: i) capital intelectual (conhecimento estratégico da organização, da cadeia de valor e indústria, bem como da complexidade que envolve as operações da empresa); ii) capital social (receptividade à diversidade cultural e a competência para estabelecer relações de confiança com pessoas de diferentes origens culturais); e iii) capital psicológico (abertura a desafios, aprendizado com base em diversos estímulos) (Fernandes, 2013).

A partir da análise dos estudos feitos sobre a liderança global (Andersson, 2000; McCall \& Hollenbeck, 2002; Harris \& Kunhert, 2007; Chong, 2008; Fernandes, 2013; Bradberry \& Greaves, 2012), observa-se que os modelos apresentam as competências necessárias e que devem ser desenvolvidas para formar um líder global de forma complementar. Para este estudo, optou-se pela proposição exposta por Javidan e Walker (2013) por apresentar de forma sistematizada as dimensões de liderança que devem ser desenvolvidas em líderes globais.

\section{Três dimensões de competências do líder global}

A partir dos conceitos apresentados sobre o líder global contata-se que o seu desenvolvimento está diretamente relacionado às competências, pois o conjunto delas é que determinará a efetividade e aceitabilidade da liderança (Javidan \& Walker, 2013). Para tanto, busca-se demonstrar através delas a necessidade do conjunto através das três dimensões (e suas respectivas competências), sendo elas capital intelectual global (conhecimento global de negócios, olhar cosmopolita e discernimento cognitivo); capital psicológico global (paixão pela diversidade, busca por desafios e autoconfiança); capital social global (empatia intercultural, impacto interpessoal e diplomacia), conforme sintetiza a Tabela 1. 
Tab. 1

Síntese das competências necessárias ao líder global

\begin{tabular}{|c|c|c|}
\hline Capital Intelectual Global & Capital Psicológico Global & Capital Social Global \\
\hline $\begin{array}{l}\text { Conhecimento Global de Negócios: } \\
\text { - Conhecimento da indústria geral; } \\
\text { - Conhecimento da competitividade em } \\
\text { negócios e estratégias de marketing } \\
\text { internacionalmente; } \\
\text { - Conhecimento do como proceder e } \\
\text { compreender riscos internacionalmente; } \\
\text { - Conhecimento de opções de } \\
\text { fornecedores mundialmente. }\end{array}$ & $\begin{array}{l}\text { Paixão pela Diversidade: } \\
\text { - Gostar de explorar outras partes do } \\
\text { mundo; } \\
\text { - Gostar de conhecer pessoas de outras } \\
\text { - Gartes do mundo; } \\
\text { - Gostar de viver em outro país; } \\
\text { - Gostar de viajar. }\end{array}$ & $\begin{array}{l}\text { Paixão pela Diversidade: } \\
\text { - Habilidade para trabalhar bem com } \\
\text { pessoas de outras partes do mundo; } \\
\text { - Habilidade para compreender } \\
\text { expressões não-verbais de pessoas de } \\
\text { outras culturas; } \\
\text { - Habilidade para se conectar } \\
\text { emocionalmente com pessoas de } \\
\text { outras culturas; } \\
\text { - Habilidade para engajar pessoas de } \\
\text { diferentes partes do mundo a } \\
\text { trabalharem juntas. }\end{array}$ \\
\hline $\begin{array}{l}\text { Olhar cosmopolita: } \\
\text { - Conhecimento de culturas no mundo; } \\
\text { - Conhecimentos em geografia, história e } \\
\text { pessoas importantes de diversos países; } \\
\text { - Conhecimento de economia e política, } \\
\text { preocupações e tópicos atuais de } \\
\text { regiões no mundo; } \\
\text { - Conhecimento atualizado de eventos } \\
\text { importantes mundialmente. }\end{array}$ & $\begin{array}{l}\qquad \text { Busca por Desafios: } \\
\text { - Interesse em lidar com situações } \\
\text { desafiadoras; } \\
\text { - Vontade de assumir riscos; } \\
\text { - Vontade de testar as capacidades do } \\
\text { outro; } \\
\text { - Gostar de lidar com situações } \\
\text { imprevisíveis. }\end{array}$ & $\begin{array}{l}\text { Impacto Interpessoal: } \\
\text { - Experiência em negociação de } \\
\text { contratos em outras culturas; } \\
\text { - Rede de contato com pessoas de } \\
\text { outras culturas e também com } \\
\text { indivíduos importantes; } \\
\text { - Reputação como líder. }\end{array}$ \\
\hline $\begin{array}{l}\text { Discernimento Cognitivo: } \\
\text { - Capacidade de rápida compreensão de } \\
\text { tópicos complexos; } \\
\text { - Capacidade analítica e de solução de } \\
\text { problemas; } \\
\text { - Compreensão de ideias abstratas; } \\
\text { - Capacidade de síntese explicação de } \\
\text { temas complexos. }\end{array}$ & $\begin{array}{l}\text { Autoconfiança: } \\
\text { - Ser enérgico; } \\
\text { - Ter autoconfiança; } \\
\text { - Estar confortável em situações } \\
\text { desconfortáveis; } \\
\text { - Ser gracioso em situações complicadas. }\end{array}$ & $\begin{array}{l}\text { Diplomacia: } \\
\text { - Vontade de iniciar uma conversa com } \\
\text { um estranho; } \\
\text { - Habilidade para integrar diversas } \\
\text { perspectivas; } \\
\text { - Habilidade para escutar o que os } \\
\text { outros têm a dizer; } \\
\text { - Vontade de colaborar. }\end{array}$ \\
\hline
\end{tabular}

Fonte: Adaptado de Javidan e Walker (2013).

Javidan e Walker (2013) organizaram esse desenvolvimento do líder global em suas competências a partir de quatro passos. O primeiro passo é aprender a partir do autodesenvolvimento, leitura e observação; o segundo passo é conectar-se, com outras pessoas, trabalhando com pessoas diferentes e aprendendo com suas experiências, bem como perguntando, questionando e debatendo, formando novos relacionamentos, aprofundando os existentes e obtendo críticas e elogios; o terceiro contempla o desenvolvimento de competências através de experiências, engajando-se em atividades de diferentes culturas, ou participando de eventos; e, por fim, o quarto passo que se caracteriza por ajudar os outros a desenvolverem suas habilidades através de aconselhamento e monitoramento pessoal e dos outros, criando informações e experiências aos indivíduos e equipes na organização.

Javidan e Walker (2013) argumentam também acerca do desenvolvimento das dimensões e, consequentemente, de suas competências, exemplificando quais são mais complexas, para serem desenvolvidas. Neste sentido o capital intelectual global é o mais simples de ser desenvolvido, pois comporta o conhecimento e como o indivíduo absorve e analisa a informação. O desenvolvimento dessa dimensão parte da leitura, escuta e observação, o que pode ser desenvolvido através do autodesenvolvimento. Entretanto o maior desafio está em desenvolver o capital psicológico global, pois envolve as experiências e personalidade da pessoa.

A essência das três dimensões do inventário do líder global inspira a possibilidade do desenvolvimento de uma mentalidade global, configurável, graduável e gerenciável, a qual será planejada de acordo com as necessidades ou entregas esperadas a partir de um contexto organizacional e global (Fernandes, 2013).

\section{Método}

Esta pesquisa é classificada como descritiva, pois esse tipo de pesquisa preocupa-se em observar, registrar, 
analisar, classificar e interpretar os dados e fatos sem a interferência do pesquisador (Raupp \& Beuren, 2008). Foi elaborado um instrumento de pesquisa de maneira que os respondentes pudessem expor suas percepções e entendimentos de maneira subjetiva e sua autopercepção de desenvolvimento através de questões objetivas. Em alinhamento com os objetivos propostos, visa-se a interpretação dos dados obtidos a partir da teoria apresentada.

A presente pesquisa possui abordagem qualitativa, pois segundo Raupp e Beuren (2008), nessa abordagem concebem-se análises mais profundas em relação ao fenômeno que está sendo estudado. As opiniões dos líderes globais questionados elucidam, a partir da percepção pessoal, o que eles creem ser o tema apresentado e o contexto de desenvolvimento da liderança global. A escolha desses líderes se justifica pelo seu contato com culturas diversificadas enquanto líderes, o que os caracteriza como lideranças globais aptas a responderem e opinarem sobre o tema e também pela acessibilidade, pois um dos pesquisadores foi aluno desses líderes durante o primeiro semestre letivo de 2014.

A abordagem utilizada para definição do grupo de sujeitos da pesquisa é a não probabilística, por acessibilidade. Os profissionais selecionados atuam tanto no meio empresarial quanto na academia na Coréia do Sul e são classificados como respondentes (R): R1, R2, R3, R4 e R5. Sendo:

R1: professor e diretor do curso de Estudos Internacionais, americano, Ph.D., um dos maiores especialistas do mundo em Coréia do Norte, atuou em empresa de grande porte alemã na China, ministrante da disciplina de Século Asiático e o lugar da Coréia do Sul;

R2: professor e empreendedor, americano, dono de empresa de marketing na Coréia do Sul com trabalhos em idioma inglês, com o nome de "Haps", trabalhando com clientes de grande porte como Kakao Talk, ministrante da disciplina de Marketing através de Fronteiras;

R3: professor, americano, já atuou em empresas como Samsung e American Express, ministrante da disciplina de Administração Intercultural;

R4: professor, líder de grupos de pesquisa com pessoas do mundo todo na área de administração intercultural/americana, ministrante da disciplina de Estratégias para o Sucesso em Organizações Globais;

R5: professor, Ph.D., americano, palestrante, radialista e ministrante da disciplina de Desenvolvimento Político e Econômico na era Global.

$\mathrm{O}$ instrumento de pesquisa foi elaborado em inglês e trata-se de um questionário estruturado com três perguntas abertas e uma questão fechada baseadas no embasamento teórico. A primeira questão aberta buscou verificar o entendimento do conceito sobre líder global. A segunda questão, fechada, foi relacionada às competências do líder global citadas por Javidan e Walker (2003) conforme consta no Global Mindset Inventory. Os respondentes deveriam atribuir uma nota de 1 (mais importante) a 9 (menos importante) de acordo com suas percepções em uma escala ordenada de relevância. Esses dados foram analisados pelo grau de importância atribuído. As questões abertas 3 e 4 identificaram a percepção dos entrevistados sobre 0 desenvolvimento das competências citadas e descrição de outras necessárias para o líder global. Em função da estrutura do questionário não foi realizado um préteste, pois a questão fechada se referia à classificação de itens previstos no referencial teórico e as questões abertas objetivavam o posicionamento amplo do respondente.

O questionário foi enviado aos líderes globais acadêmicos por correio eletrônico em setembro de 2014, tendo retornado completamente preenchido, quinze dias depois.

Os questionários foram respondidos em inglês e foram traduzidos pelos autores da pesquisa. O teor das respostas obtidas foi analisado por meio de análise de conteúdo. De acordo com Bardin (2011) a análise de conteúdo é um conjunto de técnicas de análise de dados, oriundos de um processo de comunicação, que objetiva obter indicadores que possibilitem a inferência de conhecimentos relativos às variáveis inferidas nas mensagens. A técnica utilizada neste estudo foi de categorização de elementos centrais, identificados a partir da revisão teórica realizada previamente. A categorização é uma técnica eficaz para a organização e a redução dos dados, por meio do agrupamento das informações em um número limitado de categorias (Bardin, 2011). No presente estudo foram utilizadas as categorias: (1) entendimento do conceito sobre líder global; (2) competências do líder global. Essas categorias foram 
criadas com base nas recomendações de Bardin (2011), isolando elementos para em seguida agrupálos, observando as seguintes características: (a) mutuamente exclusivas; (b) homogeneidade; (c) pertinência; (d) objetividade e fidelidade; (e) produtividade.

A codificação dos dados foi realizada sem auxílio de software, de forma manual, pelos pesquisadores, através da leitura minuciosa das respostas, destacando trechos relacionados com as categorias com marcador de texto, em diferentes cores, encaminhando a operacionalização da etapa seguinte, na qual os trechos marcados foram agrupados nas categorias já citadas.

A seguir apresentam-se os resultados da coleta de dados.

\section{Análise e Discussão dos Resultados}

A análise dos resultados se compõe a partir do entendimento do conceito de líder global (ou Global Mindset Leadership); da análise da ordem de relevância das competências do líder global; do desenvolvimento das competências do líder global e das competências complementares na visão dos líderes globais entrevistados.

Inicia-se pelo entendimento dos respondentes do conceito de líder global. Os respondentes assemelham suas respostas por apontar uma necessidade da consciência quanto ao mundo globalizado para as lideranças presentes em organizações. Contudo, alguns focam na efetividade do líder para a organização, enquanto outros apontam um cunho mais social. R1 afirma que "o tema parece bastante vago, mas creio ser a mentalidade global necessária a um líder", o que vai ao encontro do que pensa R3, que aponta: "o tema faz menção à pessoa que tenha a competência para pensar globalmente como um líder ou gerente em uma organização".

O R2 aborda que "é um conjunto de competências que faz um líder ser global, ser aceito em quaisquer culturas ou países". Para R4 "A ideia do tema é a de que vive-se e trabalha-se em uma economia global. 0 que significa que deve-se aprender diversos idiomas e estar ciente das diferentes culturas existentes". Segundo R5, o termo faz referência "ao que um líder deve ter para ser efetivo em qualquer parte do mundo, lidando com diferentes culturas e pessoas". Observa-se que as percepções dos respondentes convergem para o conceito apontado por Javidan e Walker (2013), que descrevem um conjunto de competências individuais do líder para influenciar outras pessoas, grupos e organizações de sistemas culturais divergentes dos seus, como a descrição do conceito de líder global. Hitt, Javidan e Steers (2007) determinam que o líder global deve influenciar pessoas de diferentes partes do mundo a atingir os objetivos corporativos.

Na Tabela 2, observa-se a escala de importância de cada competência de acordo com os respondentes. Para tanto, colocou-se todas as competências conforme apresentadas no referencial teórico em: conhecimento global de negócios (C1), olhar cosmopolita (C2), discernimento cognitivo (C3), paixão pela diversidade (C4), busca por desafios (C5), autoconfiança (C6), empatia intercultural (C7), impacto interpessoal (C8) e diplomacia (C9).

Tab. 2

Relevância das competências na visão dos líderes globais

\begin{tabular}{cccccccccc}
\hline $\begin{array}{c}\text { Responden- } \\
\text { tes }\end{array}$ & \multicolumn{10}{c}{ Competências } \\
\hline R1 & 71 & 3 & 6 & 4 & 8 & 5 & 1 & 9 & 2 \\
R2 & 9 & 6 & 2 & 7 & 3 & 1 & 8 & 4 & 5 \\
R3 & 1 & 4 & 8 & 7 & 9 & 2 & 5 & 3 & 6 \\
R4 & 2 & 3 & 5 & 7 & 8 & 6 & 4 & 9 & 1 \\
R5 & 9 & 7 & 5 & 2 & 8 & 3 & 6 & 4 & 1
\end{tabular}

Fonte: Elaborado pelos autores com base nos dados da pesquisa

Para a competência $C 1$, conhecimento global de negócios, R2 e R5 concluem que, face às outras, essa possui baixo grau de importância, recebendo a menor classificação entre as nove, enquanto R1 a classificou como sétima mais relevante. Não obstante, R4 a tenha classificado como a segunda mais importante, e R3 como primeira na classificação das nove. Bradberry e Greaves (2012) apontam que essa competência deve ser visualizada como recurso estrategicamente crítico, e que a performance da organização está diretamente relacionada com ela. Já Charan, Drotter e Noel (2011) a partir de estudos mostram que líderes em empresas espanholas não necessitaram dessa competência para fortalecer suas posições, o que se relaciona com as opiniões de R1, R2 e R5.

Para a competência C2, olhar cosmopolita, R1 e R4 concluem que ela é a terceira mais relevante entre as nove; R3 a classifica como quarta mais importante; R2 
a coloca como sexta mais relevante; e, R5 como sétima. Para Midler (2011) o gerenciamento do conhecimento multicultural dentro das organizações através de uma visão cosmopolita se demonstra crucial para cultivo e manutenção de relacionamentos de longo prazo no mercado internacional, assim como apontam R1, R3 e R4. Diversos projetos acabam por não ser bem-sucedidos e nem agregando conhecimento, o que de acordo com Thomas e Inkson (2009) se relaciona diretamente ao etnocentrismo, estando caracterizado a partir das respostas de R2 e R5.

Para a competência C3, discernimento cognitivo, R2 a classifica como essencial, sendo a segunda mais importante de acordo com sua visão. Já R4 e R5 a visualizam como quinta mais importante a líderes globais, semelhantemente ao que aponta R1, classificando-a como sexta mais relevante. R3 a percebe somente como oitava mais relevante. R1, R4 e R5, a enxergam com relevância mediana, o discernimento cognitivo de executivos é alvo de atenção no ambiente gerencial, o que pode caracterizar uma menor importância ao tema frente às outras competências, conforme também ressaltou R2, classificando essa com baixa relevância frente às demais.

Para a competência C4, paixão pela diversidade, R5 a classificou como segunda mais relevante, R1 a coloca como quarta mais importante. R2, R3 e R4 a classificaram como sétima entre as nove competências necessárias ao líder global. R1 e R5 valorizam mais o prazer em explorar outras partes do mundo e a satisfação em conhecer pessoas de diferentes partes do globo, pois conforme Javidan e Walker (2013) é isso que comporta essa competência. Enquanto R2, R3 e R4 pensam semelhantemente ao que apontam Pinto, Cardoso e Werther (2012), que abordam que líderes se preocupam pouco com questões de adaptação e satisfação, pois possuem outros objetivos como prioridade.

Para a competência C5, busca por desafios, R2 a classificou como terceira mais relevante ao líder global. R1, R4 e R5 a classificaram como oitava mais importante a liderança global, e R3 a classificou como a de menor relevância entre as nove necessárias ao líder global, segundo Javidan e Walker (2013).

Para a competência C6, autoconfiança, R2 a classificou como a mais importante entre as nove apresentadas, R3 a coloca como segunda mais relevante e R5, como terceira mais importante. R1 e R4 atribuíram uma classificação mediana à essa competência, a colocando como quinta e sexta mais relevante, respectivamente. R2, R3 e R5 fazem alusão a um líder global que articula um objetivo ideal ou um propósito maior ao qual se focar, e deve possuir energia suficiente para o atingimento dos mesmos, energia essa que segundo Javidan e Walker (2013) vem da própria autoconfiança. Já os respondentes R1 e R4 assemelham-se em perspectivas somente com Javidan e Walker (2013), os quais denotam que um líder global deve ser no mínimo razoavelmente confiante nas pessoas e em si mesmo para ser efetivo e aceito.

Para a competência C7, empatia intercultural, R1 a classificou como a mais importante entre as nove apresentadas. R3, R4 e R5 a classificaram como quarta, quinta e sexta mais relevante, respectivamente. $\mathrm{R} 2$ a qualificou como oitava mais importante. R2 coloca com menor relevância ainda essa competência, não crendo que a conexão com pessoas e culturas diferentes denotadas por Javidan e Walker (2013) seja de suma importância frente às outras habilidades, atitudes e comportamentos que necessitam os líderes globais de acordo com outros autores.

Para a competência C8, impacto interpessoal, R3 a classificou como terceira mais importante dentre as nove presentes nesta pesquisa. R2 e R5 a qualificam como quarta mais relevante. R1 e R4 a colocam como a menos importante entre as apresentadas por Javidan e Walker (2013). R3 expõe, conforme Javidan e Walker (2013), que um líder global tem de possuir experiência em negociações e contratos para com diferentes culturas, e uma boa rede de contatos. R2 e R5 compreendem que sua reputação irá impactar em diversos benefícios em suas organizações. R1 e R4, denotam pensar que dentre as nove competências apresentadas, a medição de como os outros os veem a partir de seus exemplos e de sua autopercepção de desenvolvimento, ou seja, sua reputação como líder, segundo Javidan e Walker (2013).

Para a competência C9, diplomacia, R4 e R5 a classificaram como a mais importante dentre as nove abordadas por Javidan e Walker (2013), R1 a qualificou como segunda mais relevante. R2 e R3 classificaram essa competência como quinta e sexta mais importante ao líder global, respectivamente. R4, R5 e R1 demonstram maior admiração a vontade e 
facilidade em iniciar uma conversa com um estranho, a habilidade para se integrar diversas perspectivas, a disposição em escutar o que os outros têm a dizer e a vontade desses líderes globais em cooperar. R2 e R3, em face às nove competências valorizam também, porém em menor escala, a premissa de que os outros possuem boas ideias, e que a diversidade de pontos de vista e perspectivas provém às pessoas maior criatividade na resolução de problemas.

Constata-se que não há unanimidade em relação à percepção do grau de importância das competências. Este resultado contribui, pelo menos, com duas proposições. A primeira diz respeito à necessidade de desenvolvimento de todas as competências, sem privilegiar uma delas. A segunda pode estar relacionada a situação vivenciada por cada respondente e, consequentemente, a competência necessária para administrar esta situação o que poderia fazer com que seja escolhida como mais importante no momento. Entretanto, percebeu-se que as competências de diplomacia e autoconfiança são as mais importantes na opinião dos respondentes e, por outro lado que a busca por desafio e o impacto interpessoal são as menos importantes.

A Tabela 3 apresenta a percepção dos líderes globais em relação às possibilidades de desenvolvimento das competências do capital intelectual global demonstradas por Javidan e Walker (2013).

Na Tabela 3 visualiza-se que para a competência "conhecimento global de negócios", os respondentes assemelharam suas respostas ao que apontam Javidan e Walker (2013), que abordam que essa competência pode ser desenvolvida através de: leitura de livros de companhias globais, artigos e publicações, aprendizado de modelos de gestão globais, contato com pessoas de diversas perspectivas, a troca de experiências entre elas e a busca por informações das indústrias de nível global.

Para "olhar cosmopolita", os respondentes também assemelham subjetivamente suas respostas à teoria apresentada, pois de acordo com Javidan e Walker (2013), essa competência pode ser desenvolvida através da leitura de notícias do mundo, troca de experiências, aprendizado de fatos históricos de um local, sua religião, participação em projeto internacional e percepção das diferentes perspectivas culturais de outros lugares do mundo. De acordo com Harris e Kunhert (2007), a transmissão de sabedoria e execução de processos de maneira efetiva propõe a visualização de perspectivas divergentes, que unidas criam um ambiente integrado e inovador.

Para "discernimento cognitivo", R1, R2, R4 e R5 se assemelham à teoria, ao passo que, de acordo com Javidan e Walker (2013), essa competência pode ser desenvolvida através da leitura, visões diferentes acerca de conceitos complexos, cursos, sínteses de conceitos complexos, estudo de matemática e filosofia. Thomas e Inkson (2009) abordam ainda que líderes devem saber como identificar oportunidades, elaborar ideias e implementar mudanças, avaliando o cenário, bem como organizando, interpretando e

Tab. 3

Desenvolvimento das competências da Dimensão Capital Intelectual Global

\begin{tabular}{cl}
\hline Competência & Ações \\
\hline \multirow{3}{*}{ Conhecimento } & R1: trabalhando em diversos países; \\
Rlobal de Negócios & R3: experiência direta em transações internacionais; \\
& R4: aprendizado através de publicações, livros e cursos; \\
& R5: leitura e questionamentos \\
\hline & R1: idiomas estrangeiros e viagens; \\
& R2: educação e experiência; \\
& R3: viagens e negócios internacionais; \\
Olhar Cosmopolita & R4: entendimento de que não há um país melhor e a compreensão de que existe uma economia global, \\
& a qual irá se tornar mais interconectada conforme o tempo; \\
& R5: leitura e questionamentos. \\
\hline R1: literatura acadêmica; \\
R2: educação e experiência; \\
R3: não pode ser desenvolvida, pessoas nascem com essa competência; \\
R4: leitura, escrita, jogar jogos complexos, discussão de problemas importantes com outros, dar \\
discursos ou ensinar; \\
R5: estudar de tudo, especialmente matemática, ciências e filosofia.
\end{tabular}

Fonte: Elaborado pelos autores com base nos dados da pesquisa. 
analisando os dados e informações presentes. Contudo, R3 afirma que essa competência não pode ser desenvolvida, o que não se assemelha com a teoria, pois segundo Javidan e Walker (2013) aquela pode ser trabalhada conforme o tempo, colocandose o líder frente a diversas perspectivas.

O desenvolvimento das competências do capital psicológico global na percepção dos respondentes está apresentado na Tabela 4. livros de autoajuda. R3 e R5 afirmam que essa competência não pode ser desenvolvida, pois é parte integrante da personalidade da pessoa, o que destoa da teoria apresentada.

Para "autoconfiança", as afirmações obtidas através dos respondentes se assemelham à teoria apresentada por Javidan e Walker (2013), pois os mesmos apontam que: pessoas diferentes possuem noções divergentes quanto ao que é considerado

Tab. 4

Desenvolvimento das competências da Dimensão Capital Psicológico Global

\begin{tabular}{|c|c|}
\hline Competência & Ações \\
\hline $\begin{array}{l}\text { Paixão pela } \\
\text { Diversidade }\end{array}$ & $\begin{array}{l}\text { R1: viajando; } \\
\text { R2: educação e experiência; } \\
\text { R3: exposição a outras culturas, contudo, depende da personalidade da pessoa; } \\
\text { R4: aprendizado de outros idiomas, culturas e história; } \\
\text { R5: viajar (em uma idade jovem). }\end{array}$ \\
\hline Busca por Desafios & $\begin{array}{l}\text { R1: leitura e viagens; } \\
\text { R2: educação e experiência; } \\
\text { R3: não pode ser desenvolvido, pois é dependente da personalidade da pessoa; } \\
\text { R4: viajar pelo mundo, fazer um novo esporte ou atividade, enfrentar seus medos; } \\
\text { R5: a pessoa nasce com isso, não pode ser desenvolvida. }\end{array}$ \\
\hline Autoconfiança & $\begin{array}{l}\text { R1: cumprimento de tarefas, atingimento de objetivos; } \\
\text { R2: educação e experiência; } \\
\text { R3: o sucesso alimenta a autoconfiança, mas ela também é dependente da personalidade; } \\
\text { R4: tornar-se um especialista em algo, aprender as forças e fraquezas pessoais, fazer coisas estimáveis. } \\
\text { Dar tempo e/ou dinheiro à alguma causa, tratar os outros com respeito e dignidade para sentir-se } \\
\text { melhor consigo mesmo; } \\
\text { R5: ganhar conhecimento e ser mais inteligente que o outro. }\end{array}$ \\
\hline
\end{tabular}

Fonte: Elaborado pelos autores com base nos dados da pesquisa.

Na Tabela 4 visualiza-se que para "paixão pela diversidade", os respondentes assemelharam suas respostas ao que apontam os autores Javidan e Walker (2013), pois abordam que essa competência pode ser desenvolvida, caso o líder assista a vídeos e filmes de outras culturas, faça viagens e exploração de outros lugares do mundo ou da própria região, se disponha à leitura de livros de literatura estrangeira e ao aprendizado de outros idiomas e culturas. Parte do que diz R3, ao afirmar que "depende da personalidade" não se relaciona com a teoria, pois os autores afirmam que essa competência pode sim ser desenvolvida, e sem limitação de idade, contrapondo também parte da afirmação de R5.

Para a competência "busca por desafios", R1, R2 e R4 assemelham suas respostas à proposição de Javidan e Walker (2013) que abordam que essa competência pode ser desenvolvida caso haja o enfrentamento de situações adversas, o desenvolvimento da sensação de conforto quando em face a desafios, um aprendizado acerca de erros e acertos, bem como uma troca de experiências e confiança, o aprimoramento em algo que se goste a fim de se tornar especialista, o cumprimento das tarefas que se propõe um líder, a troca contínua de experiências a fim de fomentar o conhecimento, a observação de pessoas que são autoconfiantes e o aprendizado sobre si mesmo e controlar os pensamentos internos resulta no aprimoramento da autoconfiança. R3 aborda que essa competência é parte integrante da personalidade o que também se assemelha à proposição de Javidan e Walker (2013), pois apontam que ela faz referência a uma sensação física interpretada à luz da experiência, ou seja, esta competência está relacionada a como o líder conhece suas competências.

A Tabela 5 apresenta, através do que os respondentes creem ser possível o desenvolvimento das competências do capital social global.

$\mathrm{Na}$ Tabela 5 visualiza-se que para "empatia intercultural", os respondentes assemelharam suas respostas ao que apontam Javidan e Walker (2013), pois os mesmos creem que essa competência pode ser desenvolvida através da exposição a diferentes 
Tab. 5

Desenvolvimento das competências da Dimensão Capital Social Global

\begin{tabular}{cl}
\hline Competência & Ações \\
\hline & R1: leitura de romances de autores estrangeiros; \\
& R2: educação e experiência; \\
Empatia & R3: pessoas nascem com a competência da empatia para um maior ou menor grau, exposição a \\
Intercultural & diferentes culturas auxilia no desenvolvimento dela; \\
& R4: entendimento de que pessoas são pessoas não importa onde vivam e aprender sobre novos idiomas \\
& e culturas; \\
& R5: viajar e interagir com diferentes pessoas. \\
\hline Impacto & R1: encontrando-se com pessoas regularmente; \\
R2: educação e experiência; & R3: pessoas nascem com essa competência em alto ou baixo grau; \\
& R4: dar discursos ou ensinar e ler livros sobre como se ter presença; \\
& R5: ser colocado em uma posição de liderança para desenvolvê-la. \\
\hline R1: praticando auto-criticismo após interação com outras pessoas; R2: educação e experiência; \\
R3: uma parte dessa competência pode ser ensinada, outra vem através de experiência e uma outra \\
ainda é um aspecto da personalidade da pessoa; \\
R4: ler a respeito de diplomacia, lidar com o stress e as decisões ruins de outras pessoas e como superar \\
os erros dos outros. Não importa se a pessoa é brilhante ou possui as melhores ideias, sem diplomacia, \\
ela irá falhar; \\
R5: escutar os outros e ter vontade de ajudar e entendê-los.
\end{tabular}

Fonte: Elaborado pelos autores com base nos dados da pesquisa.

culturas e pessoas, bem como a interação com elas a fim de compreender acerca de suas crenças e respeito aos seus princípios. O aprendizado quanto ao uso de expressões não verbais também auxilia no desenvolvimento dessa competência, assim como atividades multiculturais que conectem emocionalmente as pessoas.

Para "impacto interpessoal", R3 novamente aponta que as pessoas nascem com ela, em menor ou maior grau, ou seja, não pode ser desenvolvida, embora Hofstede, Jonker e Verwaart (2010) acreditem que o impacto interpessoal dependerá da adaptação da liderança, e ela pode ser aprimorada. R1, R2, R4 e R5 se assemelham em opiniões à teoria apresentada por Javidan e Walker (2013), pois os autores creem que essa competência possa ser desenvolvida através da experiência e aprendizado, da prática em negociações internacionais, do aprimoramento da rede de contato com outras pessoas e empresas, da percepção da reputação própria a partir de autoconhecimento e da percepção de outras pessoas e o aprimoramento disso.

Para "diplomacia", os respondentes se assemelham em opinião com os autores Javidan e Walker (2013), que apontam que ela possa ser desenvolvida através de iniciações de conversas com pessoas diferentes ou estranhos, aprendizado e experiência em como fazer uma boa apresentação, escutar o que os outros têm a dizer, compreensão das diferenças entre as próprias perspectivas e as dos outros e como elas se complementam ou podem propor melhores soluções, ser aberto ao aprendizado que outros possam proporcionar.

Questionou-se também aos respondentes acerca de competências que sejam complementares aos estudos de Javidan e Walker (2013). Os respondentes foram questionados se, a partir de sua percepção, há alguma competência que eles julguem complementar aos estudos dos autores, que apresentam nove competências. Para tanto, Ihes foi questionado quais competências eles creem não terem sido abordadas na pesquisa, até então.

R1 mencionou que um líder global necessita de idiomas estrangeiros para ser eficiente e aceito em quaisquer países ou culturas, ou seja, ter a competência para dominar rapidamente ou já possuir conhecimentos em línguas estrangeiras. R2 afirma que um líder global deve ter competência para se adaptar rapidamente, entretanto, essa já havia sido expressa pelos autores como uma habilidade pertencente à competência "impacto interpessoal", pois segundo apontam Hofstede, Jonker e Verwaart (2010), a fim de buscar na prática modelos teóricos em negociações multiculturais, os líderes globais devem demonstrar adaptação cultural em seus comportamentos. R3 aponta que um líder global, além das competências abordadas por Javidan e Walker (2013), deve possuir boa comunicação. R4 afirma que um líder global necessita de honestidade, integridade, humildade e compaixão. Mesmo os 
autores Javidan e Walker (2013) abordando que uma liderança deve ter fé ou acreditar que alguém irá agir de maneira correta, adequada ou efetiva conforme as expectativas dos seres pertencentes àquele ambiente, a teoria não aponta de maneira explícita que um líder deve ter essas atitudes quando agindo em tratativas com outras pessoas.

R5 absteve-se de elencar alguma competência complementar que achasse relevante, pois não crê haver outras mais a serem abordadas. Demonstra-se assim, que, na percepção dos entrevistados, o líder global que desenvolver as nove competências elencadas por Javidan e Walker (2013), está inteiramente preparado para trabalhos ou funções internacionais no papel da liderança.

\section{Considerações Finais}

O estudo apresentou como objetivo geral a análise da relevância do desenvolvimento das competências nas dimensões - intelectual, psicológica e social - para os líderes globais de acordo com suas percepções. A teoria apresentou que frente à globalização, a figura do líder global se faz demasiadamente necessária ao ambiente profissional, o que também é a opinião dos líderes respondentes, os quais abordam que essa liderança é canalizadora do sucesso da organização através de fronteiras e quando em interação com culturas de características e pensamentos divergentes.

Ao se classificar as competências mais relevantes ao líder global, no geral foram apontadas, primeiramente, a diplomacia e, por conseguinte, a autoconfiança. Já as menos relevantes ao processo de desenvolvimento do líder global foram, primeiramente, a busca por desafios e, por conseguinte, o impacto interpessoal.

Buscou-se também identificar como essas competências podem ser desenvolvidas na opinião dos respondentes, o que culminou por se apresentar próximo ao que crê a teoria. Ao passo que a teoria abrange um conjunto de desenvolvimento de conhecimentos, habilidades e atitudes, os respondentes abordaram de maneira sucinta a maioria desse conjunto em todas as competências apresentadas, embora um deles tenha abordado que algumas delas não podem ser desenvolvidas, o que não é opinião compartilhada dos outros respondentes, tampouco da teoria apresentada ou do pesquisador.
Perguntou-se aos líderes globais respondentes se eles acreditam haver competências não citadas pelos autores Javidan e Walker (2013), as quais seriam também necessárias ao líder global eficiente em quaisquer culturas. Contudo, três respondentes abordaram exemplos de atitudes e habilidades já integrantes das competências apontadas pelos autores, enquanto que um dos respondentes se absteve. Em contrapartida, um dos respondentes aborda o conhecimento de idiomas estrangeiros como uma competência complementar ao estudo de Javidan e Walker (2013). Essa não se encontra explicitamente dentro de alguma das outras competências abordadas pelos autores, podendo constituir a partir do conjunto de conhecimentos, habilidades e atitudes uma nova competência a ser analisada.

Os líderes ainda apresentaram sua percepção sobre a influência da cultura nos ambientes pessoal e profissional para que se atingisse o último objetivo específico, o que trouxe casos práticos de alta relevância a organizações globais, bem como opiniões pessoais divergentes de que a cultura tem alta relevância, pois um dos respondentes a coloca como secundária, sendo a execução do trabalho a prioridade no ambiente profissional e acadêmico. 0 que na verdade, denota a relevância demasiada à cultura, pois se de uma mesma nação, e sob a influência de culturas semelhantes, pessoas tendem a pensar e agir de maneiras diferentes. Caracteriza-se mais ainda a necessidade de o líder global ser adaptável não somente a países, regiões, ou empresas, mas também a indivíduos.

A partir do que estava determinado pelo objetivo foram analisados os entendimentos do conceito por líderes globais, bem como sua autopercepção de desenvolvimento das competências apontadas por Javidan e Walker (2013) como necessárias a quaisquer líderes globais. Ademais, foi verificada na opinião desses líderes qual a ordem de relevância dessas competências e como podem ser desenvolvidas.

Com relação ao problema levantado para a presente pesquisa, identificou-se que a globalização e a diferença de culturas em diversas nações e regiões pelo mundo, dá sim às empresas um ambiente cada vez mais incerto e multicultural, no qual trabalha-se com pessoas de quaisquer partes do globo. Sendo assim, a relevância do desenvolvimento das competências nas dimensões - intelectual, 
psicológica e social - de líderes globais ao mundo e às organizações se faz muito presente, pois a adaptação proveniente desse desenvolvimento é o que vai garantir a eficiência da empresa em um âmbito internacional ou local e a aceitabilidade do líder global por seus liderados em quaisquer ambientes.

Esta pesquisa teve como temática o líder global, e focou na verificação do que é e o que compõe esse líder global, bem como qual sua relevância ao mercado globalizado em que se encontra o mundo. Para tanto, responderam ao instrumento de pesquisa líderes globais dos Estados Unidos, os quais residem na Coréia do Sul e já atuaram ou seguem atuando como lideranças globais, pois estiveram e estão em contato com pessoas de diversas partes do mundo, e são culturalmente diferentes do local aonde vivem hoje.

O estudo analisou também o quão relevante é para o mundo dos negócios e acadêmico (enquanto formador de futuros líderes em organizações) a mentalidade global para líderes. A globalização providenciou ao mercado a integração de diversas culturas em um mesmo ambiente, no qual é requerido às lideranças de quaisquer organizações que possuam a consciência e competências necessárias para atuar nesses ambientes. Isso é buscado veemente por empresas de diversos setores, a fim de explorar novos mercados por vias de saturação do doméstico, ou mão de obra de valor reduzido e/ou maior especialização, entre outros motivos. Sua relevância é estabelecida por diversos líderes de mercado mundial, demonstrando que as lideranças internas da empresa são hoje os canalizadores da ideia e da cultura da empresa. Está, portanto nesses líderes globais o desafio de integrar a multiculturalidade em busca da otimização e eficiência de seus grupos. Vive-se hoje em um mundo interconectado, onde eventos em quaisquer lugares afetarão negócios locais, o que denota a importância do tema, pois pode residir nele à sobrevivência e consolidação da organização no âmbito global e local.

Conclui-se que mesmo estando ou vivendo em um mesmo país, as pessoas são diferentes. Mesmo sendo de organizações iguais, elas agem de maneira diferente. Isso, caracteriza as diferenciações de pessoas em sua maneira de pensar e agir, demonstrando assim a necessidade de mecanismos que tornem essa ação de visualizar as noções de legitimidade de outras pessoas. Sendo assim, a caracterização de um líder global está condicionada a competências que os auxiliem a aprender a respeito dessas culturas, compreender ideias mesmo que abstratas que elas possuam, aceitar que pessoas e lugares são diferentes e buscar o entendimento mútuo de todas as partes em busca da otimização.

A principal limitação deste trabalho está relacionada à quantidade e ao perfil dos respondentes, são do mesmo país de origem e atuam na mesma região demográfica, embora tenham trabalhado em locais diferentes e presenciado choques culturais diversos. Esse baixo contingente impossibilita a generalização dos dados. Contudo, esses líderes são atuantes na academia e já desempenharam papéis de liderança em organizações multinacionais e ministram disciplinas de caráter global em um curso de estudos internacionais em que há a presença de intercambistas de todas as partes do mundo.

Sugere-se a aplicação dessa pesquisa no âmbito empresarial, ou seja, um estudo de caso com direcionamento para ampliação das competências dos líderes globais. De forma adicional, sugere-se o recorte da pesquisa considerando outras culturas, levantando a estudos comparativos que possam identificar diferenças e similaridades. Deve-se para isso aplicar os questionamentos e estudar o grau de desenvolvimento das competências em cada um dos líderes globais, para após, aplicarem-se os métodos de desenvolvimento das mesmas de acordo com a convergência das percepções entre teoria e respondentes.

\section{Referências}

- Andersson, S. (2000). The internationalization of the firm from an entrepreneurial perspective. International Studies of Management \& Organization, 30(1)

- Bardin, L. (2011). Análise de conteúdo. São Paulo: Edições 70.

- Bradberry, T., \& Greaves, J. (2012). Leadership 2.0: a groundbreaking book that redefines leadership. San Diego: Talent Smart.

- Cantrell, W., \& Lucas, J. R. (2007). High Performance Ethics: 10 timeless principles for next-generation leadership. EUA: Tyndale House Publishers.

- Charan, R., Drotter, S., \& Noel, J. (2011). The Leadership Pipeline: how to build the leadership powered company. San Francisco: Jossey-Bass. 
- Chong, E. (2008). Managerial competency appraisal: A cross-cultural study of American and East Asian managers. Journal of Business Research, $61 . \quad$ doi: http://dx.doi.org/ 10.1016/j.jbusres.2007.06.007

- Fernandes, O. G. (2013). O desenvolvimento de líderes globais em unidades internacionais da indústria gaúcha: uma abordagem inspirada nos estudos de competências e Global Mindset. Unisinos: São Leopoldo.

- Harris, L. S., \& Kuhnert, K. W. (2007). Looking through the Lens of Leadership: a constructive developmental approach. Leadership and Organization Developmental Journal, 29 (1).

- Hofstede, G. J., Jonker, C. M., \& Verwaart, Tim. (2010). Cultural Differentiation of Negotiating Agents. Group Decision and Negotiation, 21(1). doi: http://dx.doi.org/10.1007/s10726-010-9190$x$

- House, R. J., Javidan, M., Hanges, P., \& Dorfman, P. (2002). Understanding Cultures and Implicit Leadership Theories Across the Globe: an introduction to Project GLOBE. Journal of World Business, 37, p. 3 - 10. doi: http://dx.doi.org/10.1016/S1090-9516(01)000694

- Hitt, M. A., Javidan, M., \& Steers, R. M. (2007). The
Global Mindset. Advances in International Management, 19. doi: http://dx.doi.org/10.1016/S1571-5027(07)19001X

- Javidan, M., \& Walker, J. L. (2013). Developing Your Global Mindset: The Handbook for Successful Global Leaders. Edina, MN: Beaver's Pond Press.

- McCall, M. W., \& Hollenbeck, G. P. (2002). Developing Global Executives: the lessons of international experiences. Boston: Harvard Business School Press.

- Midler, P. (2011). Poorly made in China: an insider's account of the China production game. Hoboken, New Jersey: Jossey-Bass.

- Pinto, L. H., Cardoso, C. C., \& Werther, W. B. Jr. (2012). Compelled to Go Abroad? Motives and Outcomes of International Assignments. The International Journal of Human Resource Management, 23(12). doi: http://dx.doi.org/10.1080/09585192.2011.61095 1

- Raupp, F. M., \& Beuren, I. M. (2008). Metodologia da Pesquisa Aplicável às Ciências Sociais. São Paulo: Atlas.

- Thomas, C. D., \& Inkson, K. (2009). Cultural Intelligence: living and working globally. San Francisco: Berret Koehler Publishers.

\section{SOBRE OS AUTORES}

- Mattheus Fontana Winck é Graduado em Administração pela Universidade Feevale. E-mail: mattheus.winck@bayer.com

- Cristiane Froehlich é Doutora em Administração pela Universidade do Vale do Rio dos Sinos. Docente e Pesquisadora do Instituto de Ciências Sociais e Aplicadas da Universidade Feevale. Coordenadora dos Cursos de Pós-Graduação Especialização em Gestão de Recursos Humanos e Especialização em Gestão Empresarial Ênfase em Serviços. E-mail: froehlich.cristiane@gmail.com. ORCID: 0000-0001-7198-6469

- Maria Cristina Bohnenberger é Doutora pela Universidade das Ilhas Baleares- Espanha. Professora e pesquisadora da Universidade Feevale.E-mail: cristin@feevale.br

- Vania Gisele Bessi é Doutora em Administração pela Universidade Federal do Rio Grande do Sul. Professora do Mestrado Profissional em Indústria Criativa, da Universidade Feevale, na linha de pesquisa Gestão e Inovação. E-mail: vania@feevale.br

- Dusan Schreiber é Professor adjunto e pesquisador da Universidade Feevale, diretor da South Konsult Consultoria Empresarial Ltda, professor adjunto das Faculdades Escola Superior de Teologia e professor titular da Faculdade IENH.E-mail: dusan@feevale.br. ORCID:0000-0003-4258-4780 


\title{
The development of the skills of global leaders: An approach based on studies of global mindset leadership
}

\author{
Mattheus Fontana Winck, Cristiane Froehlich, \\ Maria Cristina Bohnenberger, Vania Gisele Bessi e Dusan Schreiber \\ University of Feevale, Novo Hamburgo, RS, Brazil.
}

\section{ARTICLE DETAILS}

\section{Article history:}

Received 5 October 2015

Accepted 25 April 2016

Available online in 31 April 2016

Double Blind Review System

\section{Scientific Editor}

Eduardo Eugênio Spers

\section{Keywords:}

Global mindset leadership

Globalization

Competencies

Leadership

\begin{abstract}
The need of global leaders is a topic discussed in organizations. The Global Mindset Leadership is a handbook for development of the competencies of global leaders that should be able to transcend national and corporate barriers to integrate different perspectives and people and to adapt to any context. Being aware of the developments taking place in the market is the task of leaders that need to understand different cultural system and adapt to them. The objective of this research is to analyze the perception of competence development of global leaders in the intellectual, psychological and social dimensions, of the professionals that work in the academic and corporate environments. This research is classified as field research, descriptive, using qualitative approach. The main contribution of this research was to identify that global leaders are identified by competencies that make them be flexible, with a high degree of adaptation to new contexts and people. Based on the perception of active global leaders at a university in South Korea, it was possible to characterize, both in the academic and organizational perspectives, the desired profile of a global leader.
\end{abstract}

(C) 2016 Internext | ESPM. All rights reserved!

To cite this article:

Winck, M. F.; Froehlich, C.; Bohnenberger, M. C.; Bessi, V. G. \& Schreiber, D. (2016) O desenvolvimento das competências de líderes globais: Uma abordagem baseada nos estudos de global mindset leadership. Internext - Revista Eletrônica de Negócios Internacionais, 11 (2), p. 35-48.

To link to this article: http://dx.doi.org/10.18568/1980-4865.11235-48 